\title{
New Tools for Body Image Analysis: A Modern Framework Using 3D Body Scanning
}

\author{
David B. STEFAN ${ }^{1}$, David A. GILBERT ${ }^{2}$ \\ ${ }^{1}$ Novaptus Systems Inc., Chesapeake VA, USA; \\ ${ }^{2}$ The Hague Plastic and Cosmetic Surgery Center, Norfolk VA, USA \\ DOI: $10.15221 / 16.029$ http://dx.doi.org/10.15221/16.029
}

\section{Background}

Body Image Analysis (BIA) is an important area of research. It attempts to assess how the subject perceives their physical appearance, which can often differ substantially with the actual appearance of their body. One practical application is its use in qualifying bariatric patients prior to undertaking a weight loss surgery procedure. The psychologist plays as important a part in approving the weight loss surgery as the surgeon. The psychologist must undercover disorders such as binge eating and other behavioral distortions that may jeopardize successful surgical results or complicate surgical recovery. The early visual tools used for BIA were developed in the 1970s and early 1980s and have remained relatively stagnant. This paper discusses replacing the traditional $2 \mathrm{D}$ paper diagrams in use today with realistic 3D body scanning images. It also provides architectural framework options to incorporate and expand the use of a 3D body scanner within a weight loss surgery clinic or conduct BIA within a cloud based environment without the use of an on-site 3D body scanner.

\section{Scope}

Body image analysis and its related assessment tools started to become an area of study in the 1970's, and blossomed into an active field of research in the late 1980's. Most of the early focus revolved around eating disorders affecting young women and teenage girls.

This paper emphasizes body image assessment techniques for the morbidly obese. However, the ideas and architecture set forth are not limited to this area alone. It is extensible and can be applied to the traditional arenas that are concerned with body image analysis from a clinical assessment point of view. All that is needed is a large repository of relevant scan images.

\section{History of Body Image Analysis}

Body Image Analysis is something humans have been doing since early Man began walking the face of the Earth. It is something that we do either subconsciously or consciously every day. It is a qualitative evaluation. That is, we evaluate ourselves in front of a mirror, compare ourselves to others, and also compare ourselves to the myriad of images set forth in movies, television, advertisements and magazines. We also listen to the opinions of others, or overhear casual gossip and listen with interest about the features and impressions made by the appearance of others on these individuals.

This is nothing new. Everyone has at one time or another been asked, "On a scale of 1 to 10, how would you rate yourself (or him or her, or this or that)? But, this can hardly be called a scientific effort to "quantify the qualitative."

As a starting point for the discussion of body image, a reference as to just how the "ideal body" image creates itself is in order.

In many respects, what a particular society upholds as an "ideal" body image reflects their current view of physical beauty. These images have changed over time. In the distant past, there was a higher degree of geographic isolation which tended to separate one society's view of physical beauty from another's.

Figure 1 depicts $19^{\text {th }}$ century images of idealized female physical beauty from what were then relatively isolated societies. 


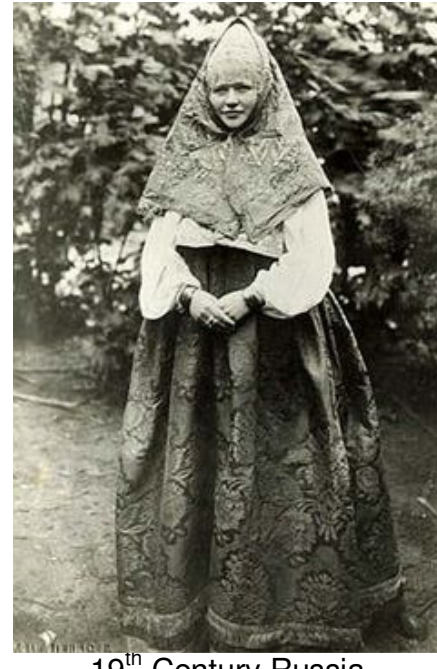

$19^{\text {th }}$ Century Russia

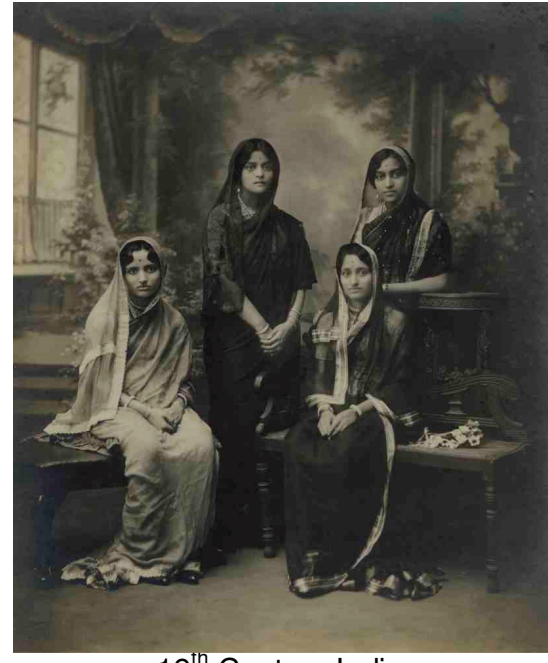

$19^{\text {th }}$ Century India

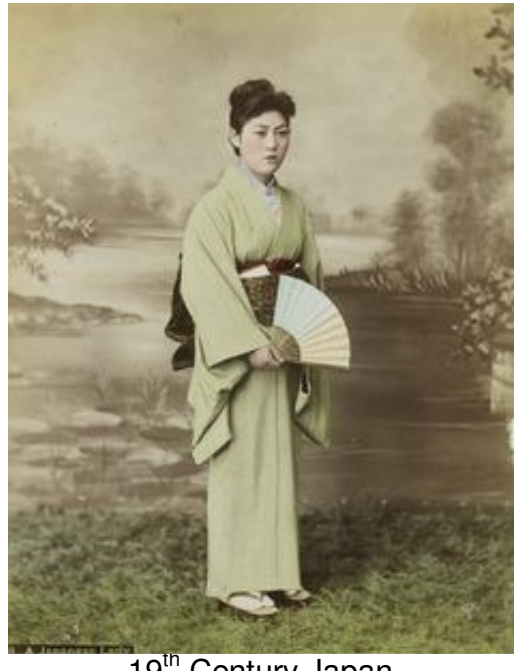

$19^{\text {th }}$ Century Japan

Figure 1. Examples of Regionalized Views of Ideal Beauty - Late $19^{\text {th }}$ Century

This began to change as the means of communication and transportation started to draw the world closer together. Clipper ships and professional illustrators, followed by steamships and the introduction and usage of photography brought back images from faraway lands of what at that time was to Western Man both startling and curious. A cottage industry of travelogues with illustrations and photographs became popular in the late nineteenth century and continued in book and subscription magazine form well into the first three decades of the twentieth century. World travelers who published these books or articles and took the photographs were highly sought after on the lecture circuits of the time.

\section{Motion Picture Industry's Influence on Physical Beauty and Ideal Body Image}

The combination of the growth of the motion picture industry in the 1920's and the distribution of its films, along with advances in photographic telegraphy, that is, the ability to send crude photographic images through telephone wires brought the world even closer. A shift began to take place. In addition to images being collected from various geographic locations, new images, developed in various film industry locations, began to be disseminated to all parts of the globe.

This was true not only of film distribution, but serial publications as well.

This marked the start of a turning point. "Ideal" body images or, more accurately, stereotypes of ideal body images began to take form that transcended community boundaries. Aside from the typical "villain with the mustache and black hat," or the "rotund boss with the fat cigar," something more insidious was happening.

Leading men and women, what we now call "movie stars," began to appear based not only on acting capability alone, but also on physical appearance. Images of "tall, dark and handsome" men, and thin but often fulsome women slowly began to erode provincial perceptions of ideal beauty.

This is not to say that a Western European or American actor or actress replaced the nominative form of ideal beauty for, say, a Japanese or Russian audience. Rather, the motion picture industry, and the leading actors and actresses within each region capable of producing motion pictures created a selective process. This process, based on popularity of the leading men and women in well-received films began to assume the cultural role of defining and presenting what could be considered the "ideal body image."

Now, instead of various cultures having only localized perceptions of "ideal beauty," figures began to appear that served as nationalized ideals.

Figure 2 depicts this shift from fragmented, parochial images of ideal beauty to nationalized images promulgated by the early motion picture industry. 


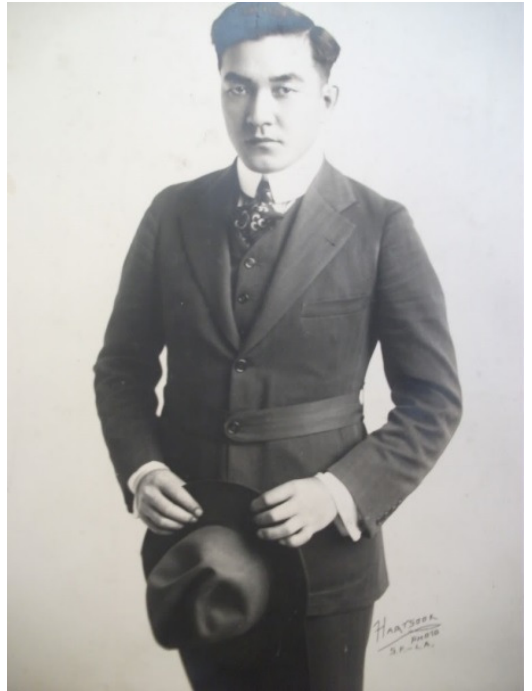

Japanese Male Ideal

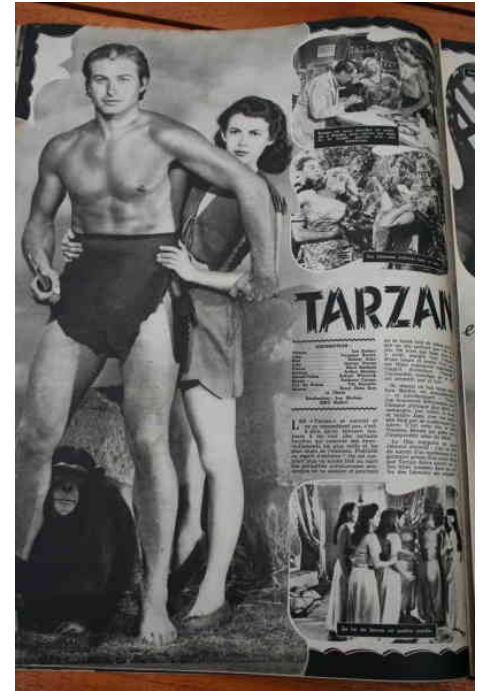

American Male Ideal

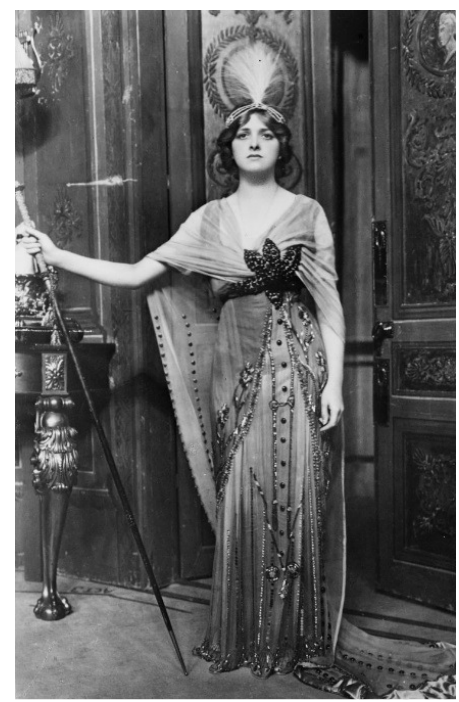

German Female Ideal

Figure 2. Early $20^{\text {th }}$ Century Views of "Nationalized" Body Ideals Promulgated by Various Motion Picture Film Centers

Coincident with the advent of mass media distribution, which had its nascent budding in the 1920's and grew very much in importance in the 1930's, was the combined effects of the world wide depression and the large scale introduction of agricultural machinery.

1933 was known as "Hungry '33." There were a number of famine stricken areas around the world. In the midst of a world-wide depression, prices for agricultural commodities plummeted. Farms and farm machinery were often repossessed by banks that had yet to fail. Yet the ideal body image for both men and women continued to be promulgated, despite the conditions of the time. This gives some credence as to the durability of the ideal body images established via the film industry.

\section{Academic Interest in Body Image Assessment Begins}

In the midst of this backdrop, a man named Paul Schilder, published "The Image and Appearance of the Human Body." The cover of which is shown in Figure 3. This was in 1935. He was the first one to coin the term "body image." Schilder emerged as the scholar who "almost single-handedly upgraded the study of body experience, taking it beyond a parochial focus on the distorted perceptions induced by brain damage."

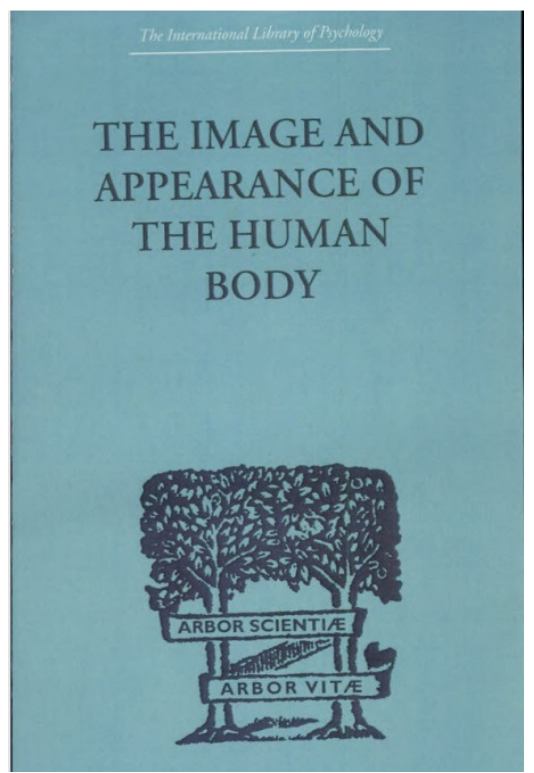

Figure 3. First Academic Work on Body Image Analysis, 1935 


\section{Technological Progress Led to Surplus of Food and the Emergence of Processed Foods}

Over time, with the application of agricultural machinery and modern farming and ranching methods, a surplus of food stocks became common. Simultaneous with the widespread availability of home appliances in the mid 1950's, we began seeing the first of a wave of processed food. Frozen food that was already "cooked" and only needed to be reheated and served. We began seeing "fast food" restaurants dotted along highways that competed with more traditional "sit down" restaurants. This continued throughout the 1960s and early 1970s, and, of course, they are prevalent today. Advances in pesticides, fertilizer manufacturing and land management practices combined to yield more and more crops per acre.

In 1957, a process that could convert the mildly sweet glucose in corn into very sweet fructose was discovered. This went into production on an industrial scale in the mid 1970's and was used as a replacement for conventional sugar. The United States placed tariffs on imported sugar, in 1977, thereby raising the price of domestic sugar and made it more expensive to use than high fructose corn syrup as a sweetener in processed foods and beverages ${ }^{3}$.

It may or may not be a coincidence, but the first reports of an increase in obesity began to get national attention in the mid-to-late 1970s. Figure 4 depicts this in chart form. Note the increase in the obesity rate starting in the late $1970 \mathrm{~s}^{4}$.

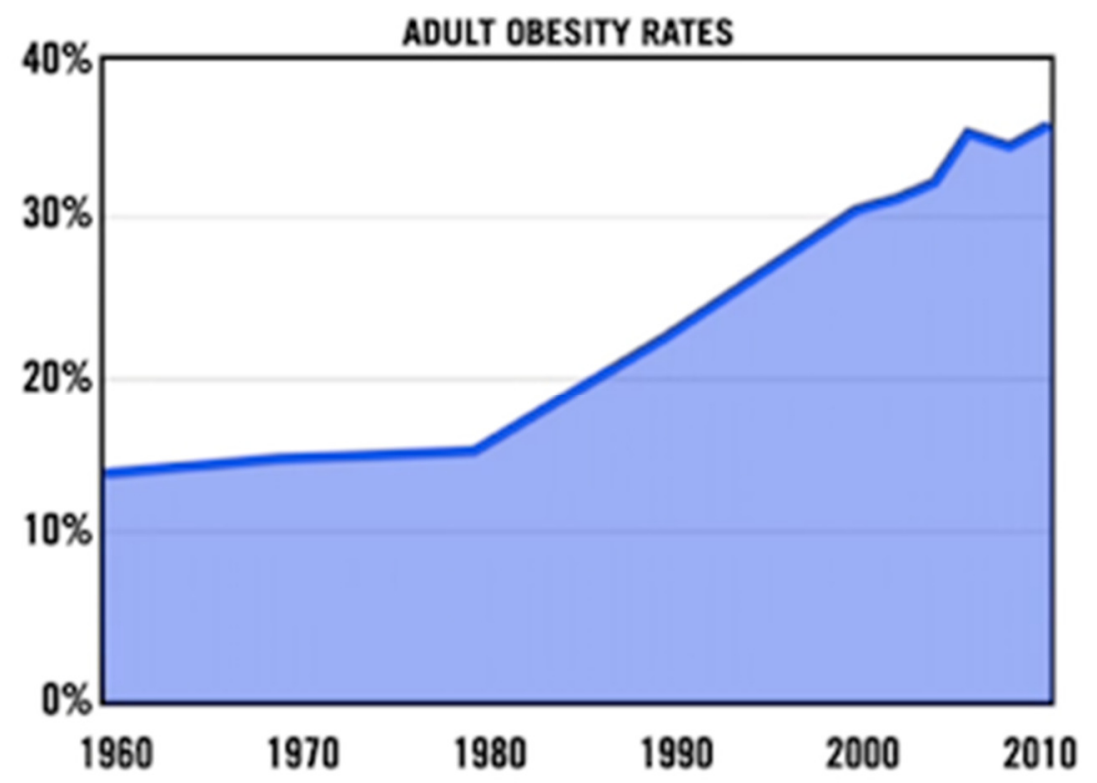

Figure 4. American Adult Obesity Rates (Courtesy economistsview.typepad.com)

\section{Academic Interest in Body Image Analysis Emerges as a Field of Study}

In the 1970s, heightened interest began to appear on the topic of body image assessment. Eminent psychologist Seymour Fisher devoted much of his career to studying body image from a psychoanalytic perspective, prolifically publishing books and scientific papers on what he called the "body boundary" construct ${ }^{5}$. One of his works was "Body Experience in Fantasy and Behavior," published in $1970^{6}$, but referred to constantly throughout the seventies in academic circles as cases of Anorexia Nervosa and Bulimia Nervosa started to be diagnosed.

The purpose of this particular paper is not to furnish an opinion or speculate on the root causes of body dissatisfaction. Rather, it is to point out to the reader that the influence of media images through its vast distribution network, and technological advances in the production, storage and distribution of food have combined in such a way as to pose a contradiction to the average citizen, without regard to age group. 
On the one hand, men and women consciously or unconsciously aspire to have a body image consistent with what mass media, supposedly a reflection on society, considers to be "ideal." We have seen how this is a selective process, particularly in the film industry, whereby those gifted with physical attributes tend to rise in popularity. And popularity means amplified media coverage through its various outlets. This is true for all age groups to a certain extent. Such images are often impossible to attain and are generally unrealistic for the great mass of people. Figure 5 displays current views of what may be deemed as "ideal" national female body images per their respective popular media.

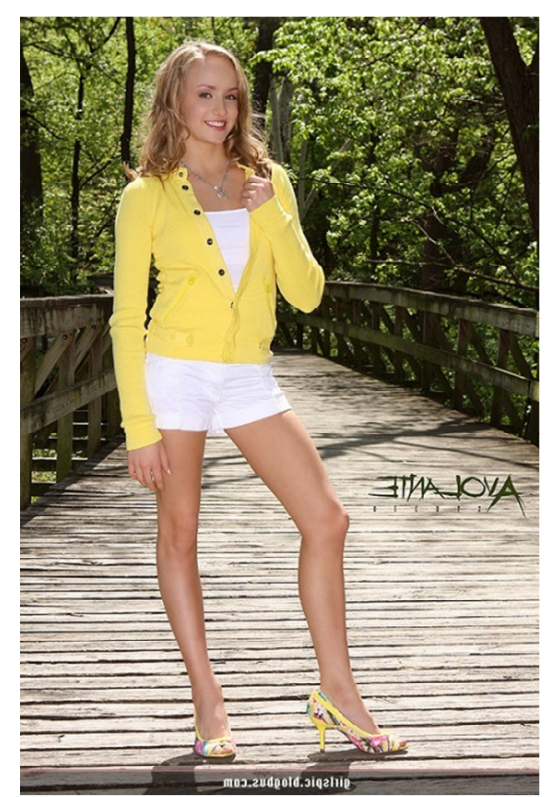

Modern-era Russian Film Star

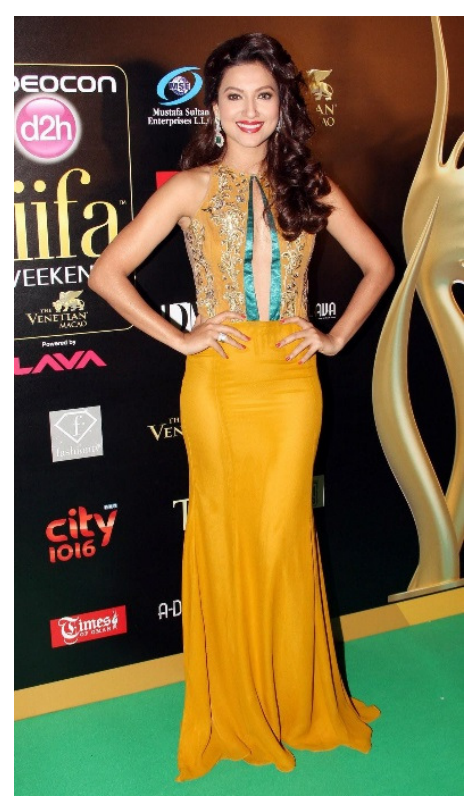

Modern-era Indian Film Star

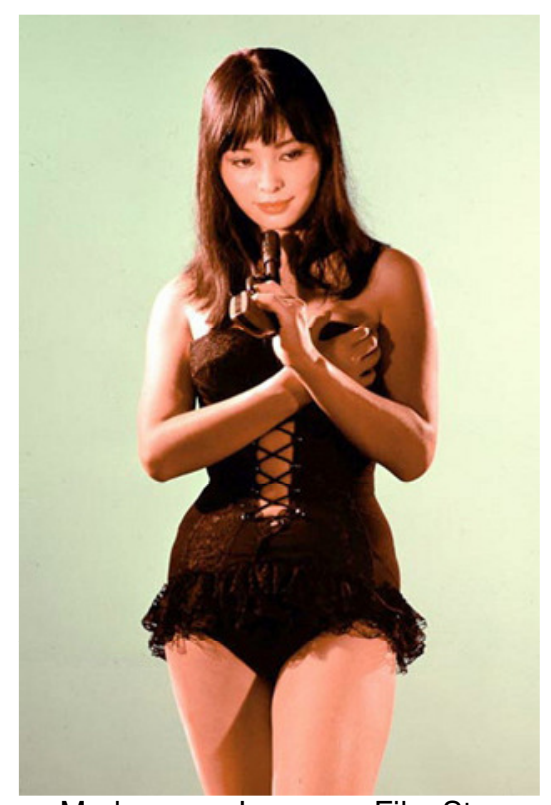

Modern-era Japanese Film Star

Figure 5. Similarities in Today's Female 'Ideal” Body Images, Regardless of Nationalities (in Contrast to Figure 1).

On the other hand, the abundance and availability of inexpensive mass produced processed food, easily obtainable through its vast distribution network may contribute to certain health disorders, such as "binge eating," and obesity. This is in contradistinction to pursuing the body image ideals promulgated through media outlets.

It is small wonder that many people, through the various influences encountered every day, have some sort of dissatisfaction with their physical appearance.

This, given the circumstances, is normal. What is not necessarily normal is the distortive effects that one's own mind may play on the accurate evaluation of one's own body appearance and body satisfaction.

\section{The Beginning of Quantitative Assessment Techniques}

Some of the first efforts to transcend what was at that time a mostly qualitative initiative into tests that could be quantified and scored came with the introduction of survey methods.

Interrogatories such as the Body Image Assessment (BIA) and Body Shape Questionnaire (BSQ) surfaced in the 1990's and early 2000's. These were followed by other surveys such as Body Image Dissatisfaction and even a Body Parts Dissatisfaction Questionnaire?

There are many variations available, such as the number of questions on the survey. Figure 6 depicts a BSQ with 8 questions that concentrate over four weeks of time. Other BSQs of note have more questions and/or focus on different time periods or longer time frames ${ }^{8}$. 


\section{BSQ-8A}

We should like to know how you have been feeling about your appearance over the PAST FOUR WEEKS. Please read each question and circle the appropriate number to the right. Please answer all the questions.

\section{OVER THE PAST FOUR WEEKS:}

1. Has feeling bored made you brood about your shape?

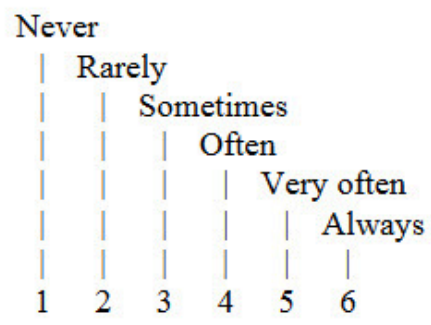

2. Have you thought that your thighs, hips or bottom are too large for the rest of you?

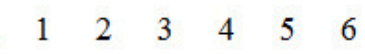

3. Have you felt so bad about your shape that you have cried?

4. Have you avoided running because your flesh might wobble?.......

5. Has being with thin women made you feel self-conscious about your shape?

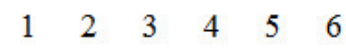

6. Have you worried about your thighs spreading out when sitting down? $\begin{array}{lllllll}1 & 2 & 3 & 4 & 5 & 6\end{array}$

7. Has eating sweets, cakes, or other high calorie food made you feel fat? $\quad \begin{array}{lllllll}1 & 2 & 3 & 4 & 5 & 6\end{array}$

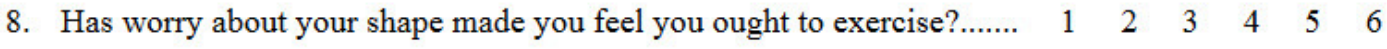

Figure 6. Example of a Body Shape Questionnaire with 8 Questions over 4 Weeks' Time

Much of the clinical psychology and psychiatry that dominated the study of body image in the early years have been investigations and applications pertaining to eating disorders among young women. Soon, studies were generated that included more age groups and the focus of these efforts widened the scope of research.

\section{Figural Stimuli Appear as an Aid in Body Image Assessment}

These studies were accompanied by "figural stimuli" in the form of silhouettes which depict body shapes that ranged from extremely thin to morbidly obese.

Figure 7 below displays a commonly used set of figural stimuli, for both male and female. They are generic in nature and wholly generalized. This particular set is commonly known as "Stunkard Diagrams," after the psychologist, Stunkard, who introduced this technique ${ }^{9}$. 


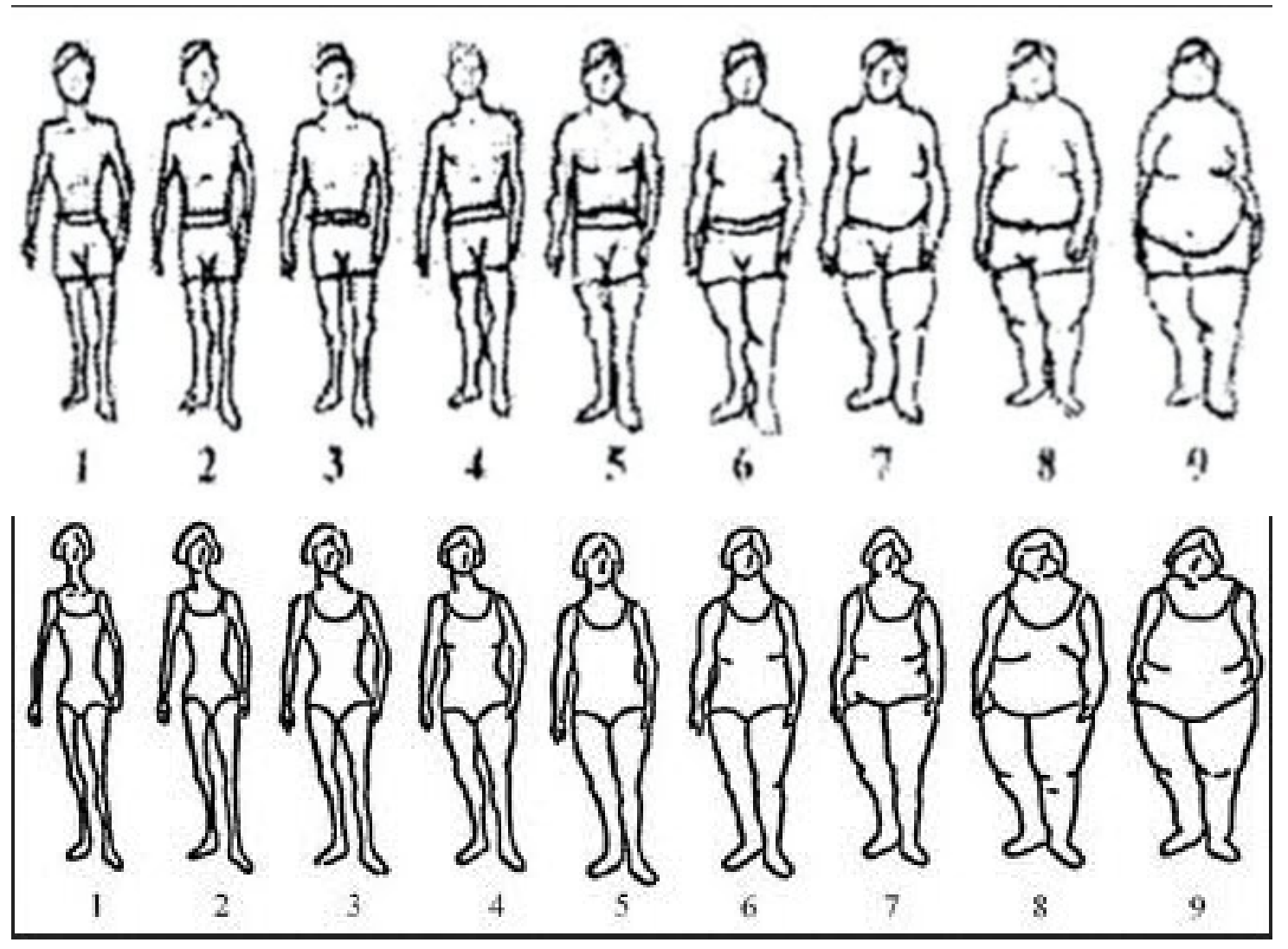

Figure 7. Male and Female Figural Stimuli Diagrams

Note that each of the figures are numbered. Though this isn't a technical scoring system, it allows the analyst to keep track of the figures within the set that are selected.

A typical sequence of questions might start by asking the individual "Which figure within the set do you feel most represents your body shape?" Another question would be "Given your selection of your current shape, what would you consider your ideal shape to be?" Yet another question would be "What body shape in the set would you be satisfied to maintain over time?"

These early studies provided some helpful insight into research as to how participants perceived their particular body shape and image, and were (and still are) extensively used in the study of anorexic and bulimic conditions.

\section{Body Image Assessment Starts to Address the Obese in $\mathbf{2 0 0 0}$}

In 2000, a paper was written that modified the Body Image Assessment Survey to include obese subjects. It was titled "Body Image Assessment for Obesity (BIA-O): Development of a New Procedure." 10

Figure 8 displays the extended set of figural stimuli used for this research. 
October 2000, Volume 24, Number 10, Pages 1326-1332

Body image assessment for obesity (BIA-O): development of a new procedure

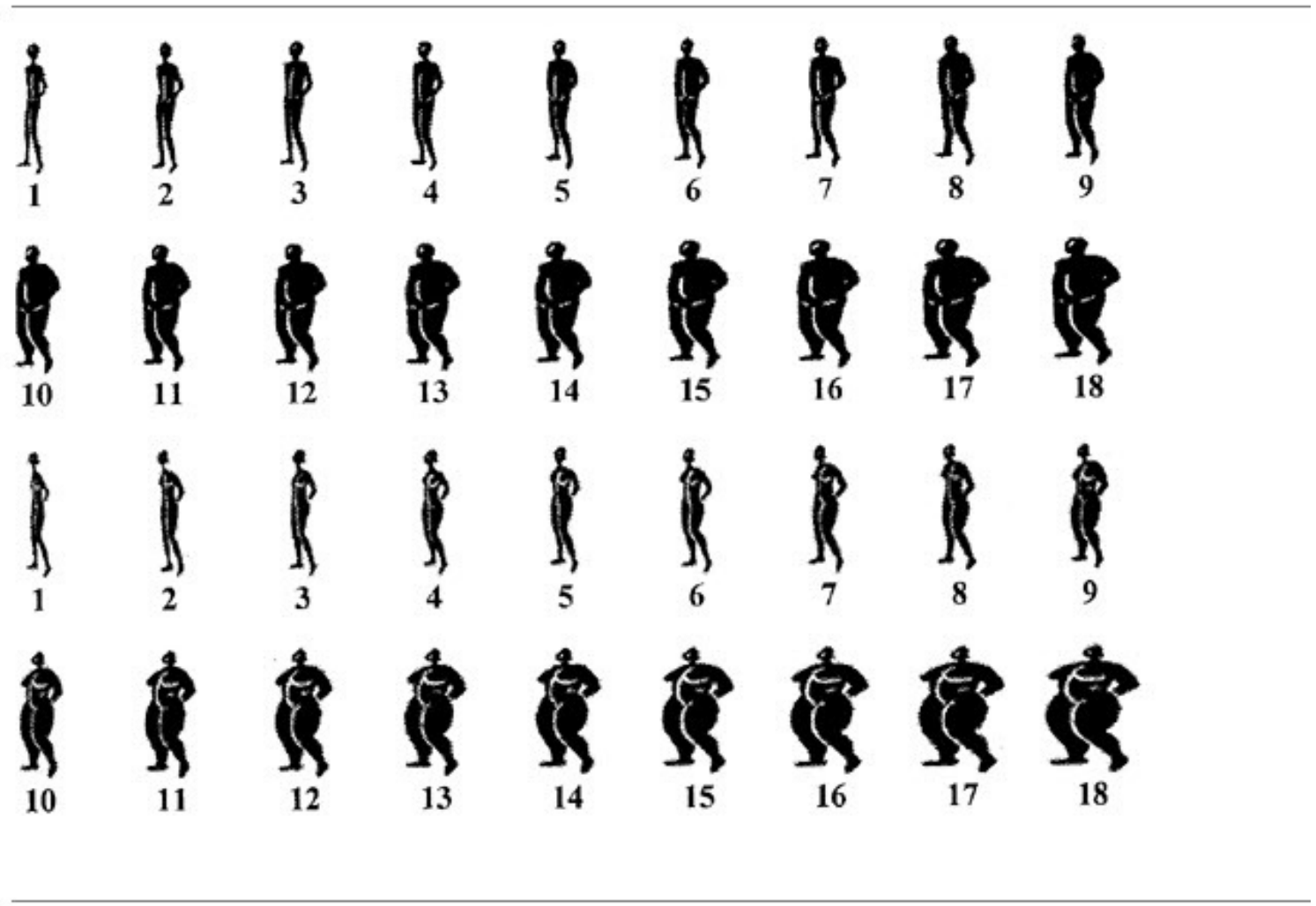

Figure 1 BIA-O figural stimuli for men and women. The numbers (1-18) are the raw scores for each silhouette. Male silhouettes are shown at the top of the figure and female silhouettes are shown at the bottom of the figure.

Figure 8. Extended Set of Figural Stimuli to Address Obese Shapes

A sample of 1209 adult men and women were given figural stimuli for body sizes ranging from very thin to very obese in 18 increments. These subjects ranged from thin, normal size and obese, as defined by their BMI. However, very few of the subjects in this study were considered morbidly obese, as defined by possessing a BMI of 40 or greater.

Instead of presenting the entire set as a whole, each figure was placed on a separate, numbered card and presented to them in random order. The subjects were asked to "Select the silhouette that most accurately depicts your body size as you perceive it to be. Please be honest. You must choose only one silhouette and you may not rearrange the cards to directly compare different silhouettes."

The experimenter then recorded the card number (1-18) which was written on the back of the card, so the participant couldn't use the number as an aid in selecting a body size estimate.

The cards were reshuffled and presented in a new random order. The participant was then asked to "Please select the silhouette that most accurately depicts the body size that you would most prefer." This number was recorded.

The cards were reshuffled for a third time. The participant was then asked too "Please select a silhouette that represents a body size that you believe is realistic for you to maintain over a long period of time."

A Body Shape Questionnaire was then administered, and a Body Dissatisfaction Scale of Eating Disorder was selected as a second measure of body dissatisfaction.

The mix of subjects contained both Caucasian and African-American men and women with widely ranging height and weight. There were several conclusions. 


\section{Conclusions of the BIA-O Paper}

Caucasian men and women routinely selected initial shapes that were comparatively larger than their African-American counterparts. African-American men and women routinely chose initial shapes the were comparable to the underweight to normal body range.

Caucasian men and women routinely selected ideal shapes that were thinner figures than AfricanAmericans, but this difference wasn't statistically significant.

African-American women do not perceive themselves to be as obese as their Caucasian counterparts.

African-American women do not prefer an extremely thin body size.

African-American women and men perceived less discrepancy between their current and ideal body size estimates.

In their summary, the authors posited that "These measures may reflect cultural standards for ideal body size, as opposed to rational standards based upon current scientific knowledge about weight regulation, i.e. obese persons are not likely to achieve a truly thin body shape. If this speculation is correct, these data illustrate the extent of the challenge for weight loss counselors who attempt to modify expectations pertaining to a realistic weight goal for most obese patients."

In other words, those that were obese did not have a reasonable assessment of their body, further, the perception of what weight loss could be reasonably expected to achieve their maintainable shape by traditional means were unrealistic.

The extremely obese and, the next level up, the morbidly obese are to be found in numbers sufficient for large scale study at one convenient location, the clinical weight loss surgery center. When a subject reaches a certain stage of obesity, such as the "morbidly obese" condition, they do not have a particularly good perception of their size or their shape, although they certainly understand that something "proactive" must be done. Traditional weight loss methods probably were already tried and had limited effect. At this point, weight loss surgical procedures thus provide the best path to achieve a positive outcome.

That is, if the patient qualifies for the procedure.

\section{The Two Paths to Approval for Weight Loss Surgery and the Role of the Clinical Psychologist $^{11}$}

It is a misperception to believe that all morbidly obese individuals qualify for a weight loss surgical procedure.

This may be because the individual has certain medical conditions that may complicate the surgery and therefore they pose an undue risk. These risks are physiological in nature and are assessed and addressed by the surgeon as part of the pre-operative evaluation process.

The other qualification path requires an "emotional" approval. This is where the clinical staff psychologist comes to the forefront. The psychologist must uncover and evaluate any behavioral disorders, actual or potential, that may lead to improper pre-operative preparation, or post-surgical conformance issues.

The American standard at present for an individual to be considered for weight loss surgery is for that individual to possess a minimum BMI of 40 . There are exceptions to this. A person could possess a BMI of 35 , but must also have certain co-morbid complications (diabetes, high blood pressure, high cholesterol, hypertension, sleep apnea, etc.).

The great majority of individuals who enter the evaluation process possess BMI values much greater than 40. Many arrive with certain medical complications already established, and many arrive with certain psychological disorders. These disorders, as one might suspect, include certain eating disorders. However, other disorders can also play a role that may have contributed to their morbidly obese condition.

Some individuals present with a morbidly obese condition based mainly on biological predisposition and have little or no other medical complications. Regardless, all who enter a weight loss surgery program must be evaluated by the psychologist. 
The psychologist begins by investigating the individual's pathophysiology. These include individual and familial factors associated with eating disorders, including difficulties in self-esteem and selfregulation, along with a sense of ineffectiveness and helplessness.

Sociological factors are also investigated, such as peer groups or social pressure and repeated but failed diet or exercise efforts.

Affective disorders, especially depression are not uncommon among the morbidly obese. This must be addressed.

The psychologist investigates other psychiatric conditions, such as obsessive-compulsive disorder, personality disorders involving impulsivity, phobias or general anxiety disorder.

When the investigation and evaluation is completed, the psychologist either affirms or rejects the individual as suitable or not suitable for a surgical weight loss procedure. If the psychologist deems that the individual in question is not emotionally prepared for the procedure, they are generally referred to counseling to address specific issues uncovered during this process.

This all leads up to the question: "Is the patient "ready" to lose weight?" And its corollary: "Do they have an understanding of their current body image and realistic expectations of weight loss?"

\section{The Early Efforts using a 3D Booth Scanner for Body Image Assessment of the Morbidly Obese}

3D booth-type scanners began appearing around the year 2000. These were either very expensive laser scanners, or less expensive but very large white light scanners that had heavy mechanical projectors. For all practical purposes, the size of the early 3D white light scanners made them impractical for use in most clinical settings. There are also strict guidelines to introducing equipment into the medical environment if humans are the subject of research.

Improvements in camera and projector technology evolved to the point where there were multiple vendors with multiple scanner offerings.

Academic researchers began applying these "new" devices to contribute to the ongoing study efforts underway for body image assessment. The focus was on augmented and/or replacing traditional silhouette form figural stimuli and automating the tabulation of survey results ${ }^{12}$.

Figure 9 depicts a composite of some of these efforts.

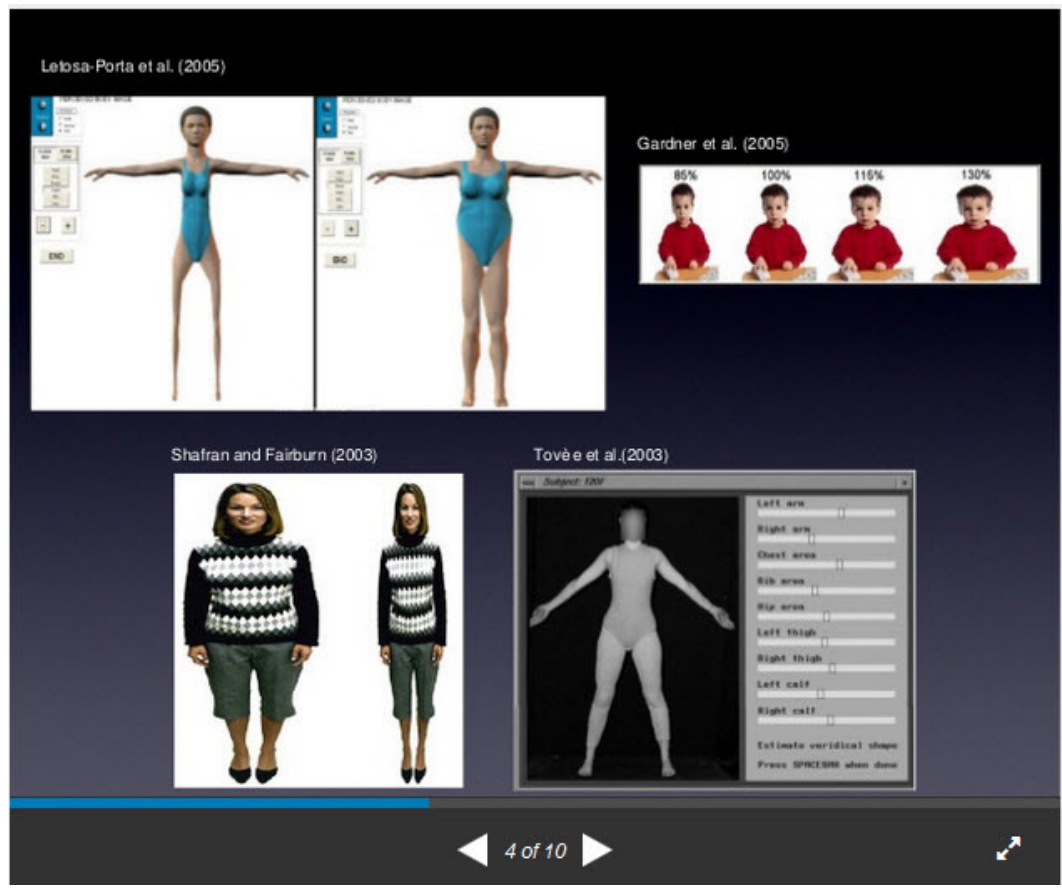

Figure 9. Early Digital Figural Stimuli Efforts 
Further efforts were made with a digital camera and computer system, as shown in Figure 10.

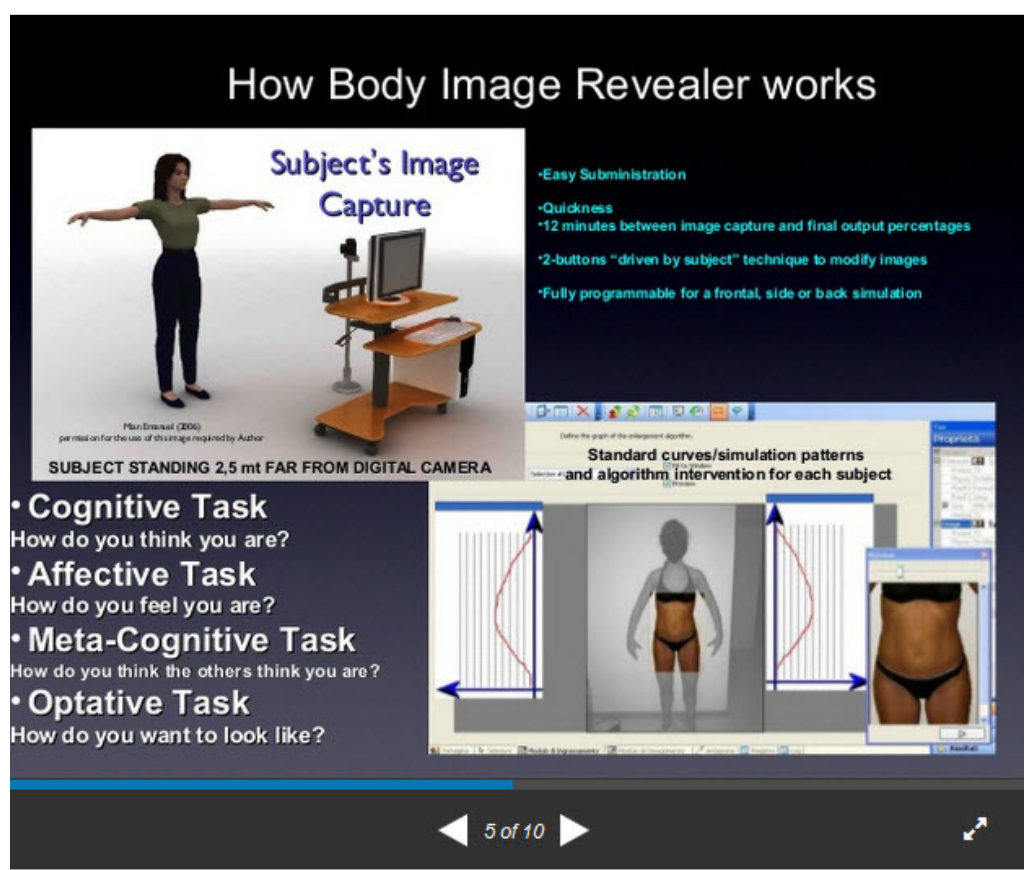

Figure 10. Digital Imaging System for Body Image Analysis

These efforts were valuable in that they brought new technology, previously unavailable, to help bridge the gap between traditional two-dimensional, generalized figural stimuli crossing over to a more personalized approach to body image assessment.

They also proved that the need for generalized figural stimuli is still required.

It has been the author's experience and observation that in order to understand one's own body image, you have to have something to compare it to for reference. This is particularly true with the morbidly obese. To have this be effective, there must be a great number of scans that can be segmented into body shapes that the morbidly obese can identify with.

\section{D Figural Stimuli Created from 3D Booth-type Body Scanners}

For a number of years, a 3D booth-type scanner has been deployed in a very active bariatric surgery clinic. The utility of such as scanner has proved its value by documenting the body shape and recording measurements of pre-operative weight loss surgery patients. Individuals are scanned during routine post-operative office visits and their body shape and measurement changes are recorded. Pre-operative and successive post-operative body scans are compiled into a "Weight Loss Storybook," which includes charts and tables of their measurement changes, printouts of each scan, and a superimposition of their post-operative body model which is overlaid on their pre-operative scan image $^{13}$.

The Storybooks give perspective to the individual by not only providing common circumferential measurements changes as they undergo massive weight loss, but also a visual aid that allows them to view there "new body" within the confines of their pre-operative shape.

As part of the preoperative evaluation procedure, each surgical weight loss candidate receives a printout of their scanned body model. Such a printout includes their front and side profiles, and common circumferential measurements that the individual can easily understand.

Of course, there is nothing unique about this particular feature. However, the use of such printouts for the preoperative morbidly obese and their responses when "confronted" with their body image and measurements in the form of a simple printout produced remarkable responses.

For most, it was the first time that they could view their body objectively. The general size of the morbidly obese often prohibits the use of basic measuring tools, such as a common tape measure. 
The general interest that these individuals displayed in their body image and their common circumferential measurements sparked an effort to create body image assessment tools for the morbidly obese.

The 3D body model captured by the booth scanner can be exported to many popular CAD packages. An effort was made to develop more realistic and personalized "figural stimuli." Morbidly obese individuals' 3D body models captured by the body scanner were exported to such a package. The 3D body model itself is composed of thousands of points that outline the surface of the body model. These points are typically in Cartesian coordinates, with the origin $(0,0,0)$ at the center of the floor of the scanner. The points on the surface can be connected to each other, forming an "edge," when three points are connected together, they form a "facet," or triangle shape. This allows surface area to be calculated. Multiple triangles can be connected in such a way as to form polygons. When all such points on the surface area connected in this way, three-dimensional information, such as volume, in cc, can be generated.

Body models are generally constructed from "raw" binary files collected from the cameras utilized by the scanner to form a single, large binary file. This binary file is too cumbersome to manipulate and extract measurements. Software provided with the scanner system reduces the large binary file into a smaller file that can be processed more readily.

Some vendors produce "component" parts of the body that can be individually measured. This could include right and left arms, right and left legs and a torso, which generally does not include measurements of the head. Other vendors reduce the binary file into a single body model file.

Regardless of the type of body model produced, volumetric information, at least in regards to the whole body and the torso are retained. This is an important point. Since the body model represents the proportionally correct image of the subject, one can then keep the $y$-axis, or height of the body model fixed and scale the $X$ (width) and $Z$ (depth) axes to produce different volumetrically accurate body models within the CAD program.

Volume and weight have a definite, but not exact correlation. The lower the volume, given a fixed yaxis, the lower the associated weight. The converse also holds true. Figure 11 displays an example of accurate volumetric scaling of an obese $3 \mathrm{D}$ body model ${ }^{14}$.

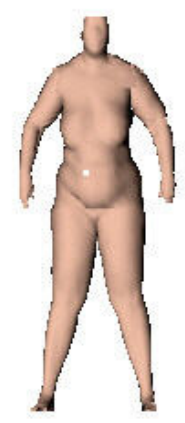

$25 \%$ Actual Size

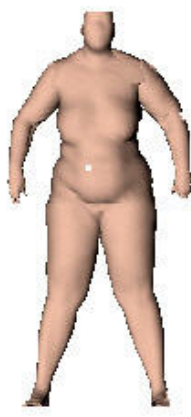

$50 \%$ Actual Size

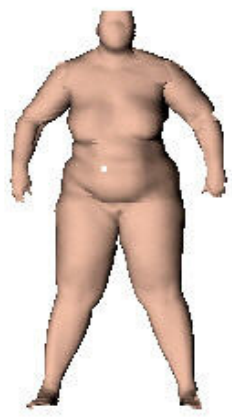

$70 \%$ Actual Size

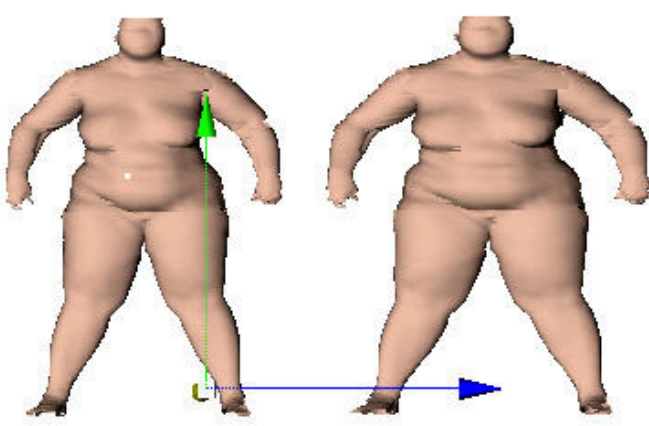

Actual Size of Pre-op Patient
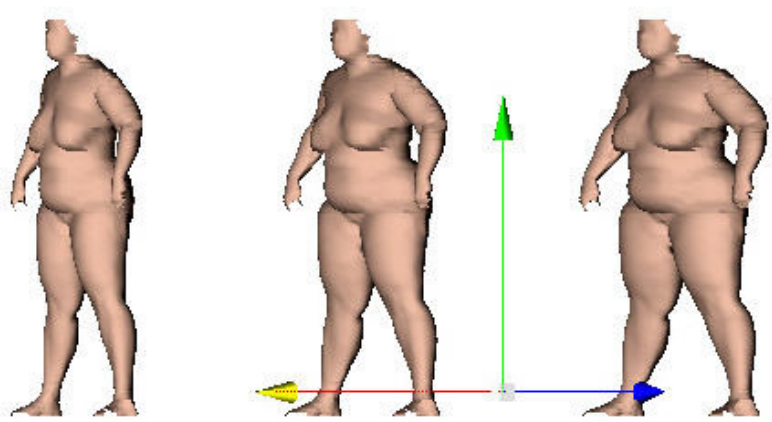

Figure 11. Accurate Volumetric Scaling of an Extremely Obese 3D Body Model 
The first attempts at producing such realistic "figural stimuli" for body assessment purposes were not entirely well received. Even though they appeared to be more realistic and accurate than existing figural stimuli, the author found that most morbidly obese individuals needed a reference body shape for which to compare themselves.

They may have understood their particular body shape, from the front and side images within the printout, and they had knowledge of their circumferential measurements since they were recorded and presented with their images. What they lacked was the ability to compare themselves to others, particularly those that were in their same circumstances, that is, those who were morbidly obese as well.

This is where the Shape Descriptors took a role. The theory and development of the Shape Descriptors have been presented in numerous papers in the past. The reader is encouraged to review the numerous references to understand the theory behind the Shape Descriptors and their use in determining weight distribution on the torso of an overweight individual ${ }^{13,14,15}$.

Analysis of the thousands of 3D scans of female pre-operative weight loss candidates has led to the segmentation of morbidly obese female body shapes into six "top-level" shapes. These are depicted in Figure 12.

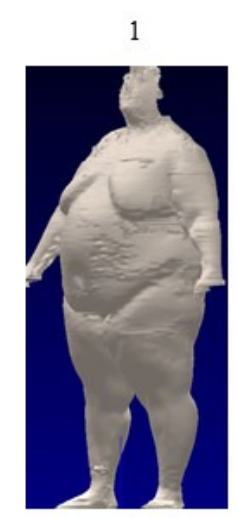

Extreme Gynecoid 85

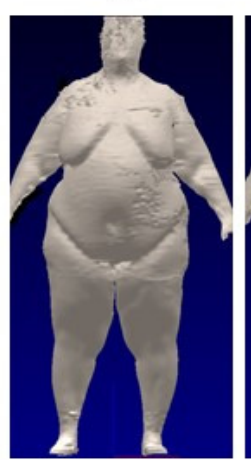

1

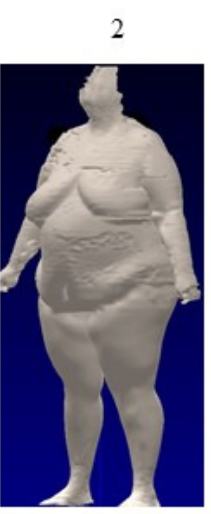

Gynecoid.

.80

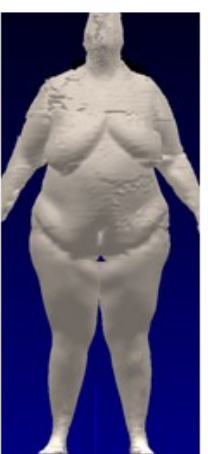

2

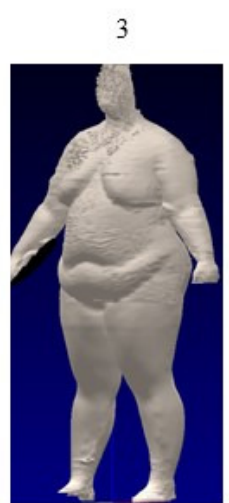

Gynecoid

Mixed

0.77

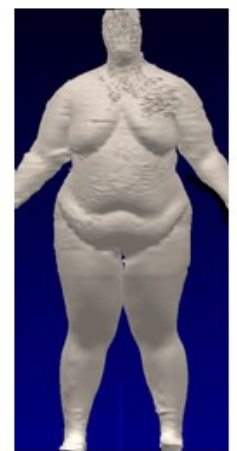

3
4

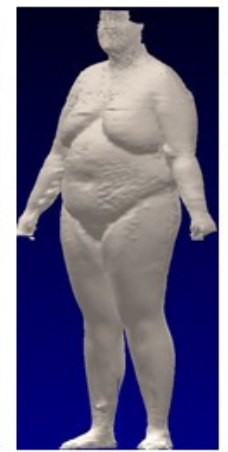

MIXED

.75

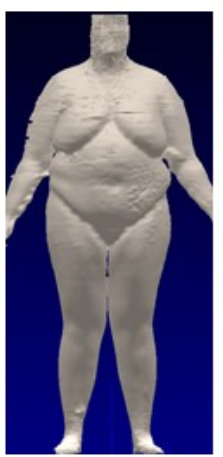

4
5

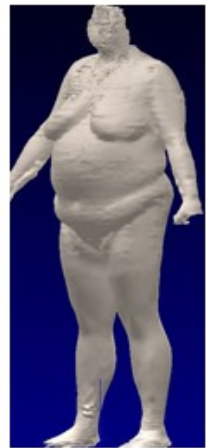

Mixed

Android

0.73

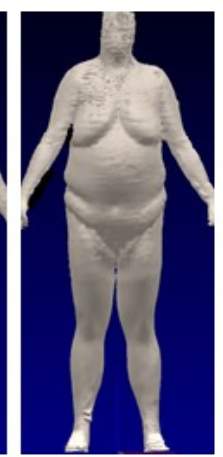

5

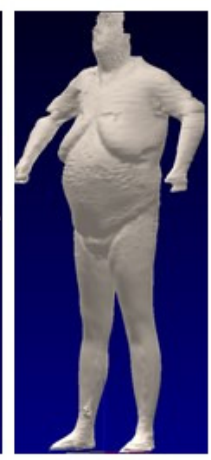

Android

70

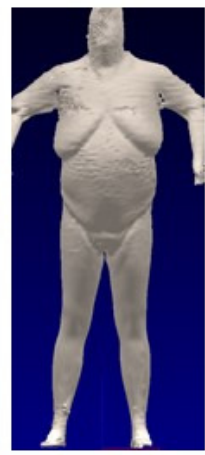

6

Figure 12. Six "Top Level" Shapes for Morbidly Obese Females Based on Statistical Analysis of Primary Shape Value

These are the body shapes that can be "identified with" in that the shape is similar to their own. Not exactly the identical shape that they possess, but close enough that they can feel some association.

This is an important point. It seems you can't do effective body image assessment in isolation. Individuals need a reference shape with which they can relate.

It also provides the means to perform Body Image Assessment without the direct need for a 3D body scanner at the clinical site, though without this option there is a lack of personalization. The top level shape images displayed in Figure 12 are not stylized and are rather rough. This can be changed if it is felt that colorized images work better. 
Once the top level shape is selected by the individual as the shape she most readily identifies with, another sub-section of body shapes is displayed. These should be more personalized. An example of such an array of shapes is depicted in Figure 13.

1

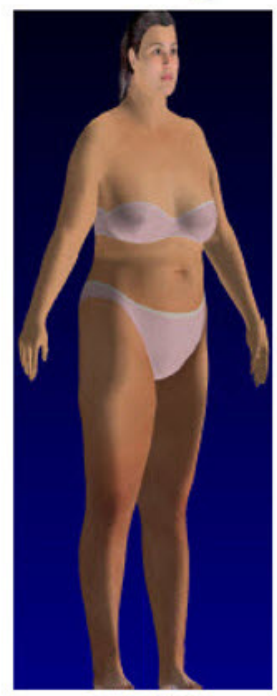

1
2

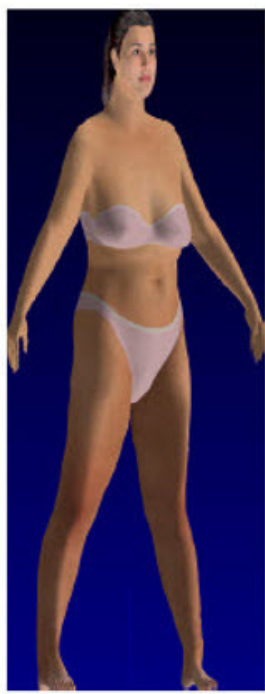

2
3

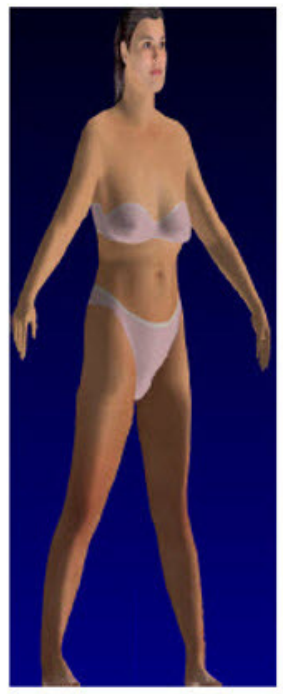

3
4

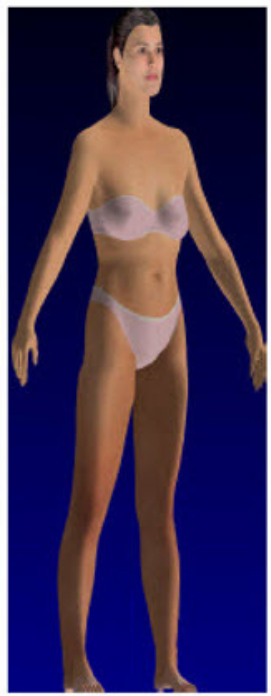

4
5

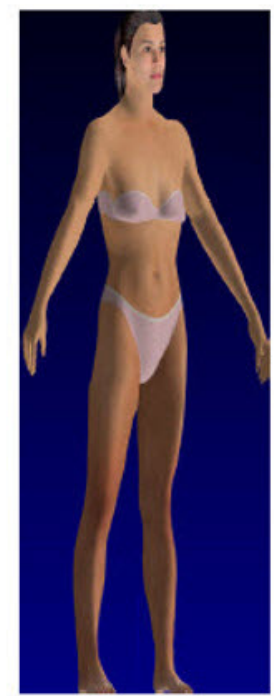

5

Figure 13. Specific Subset of Shapes under the Selected Top Level Shape

Note that each individual shape displayed in Figures 12 and 13 have a number associated with them. This allows the particular selection/selections to be tabulated and recorded, along the lines of previous assessment tests associated with earlier 2D figural stimuli.

\section{Updated Architectures for Body Image Assessment of the Morbidly Obese}

It is at this point that two architectures emerge for body image assessment. One architecture requires an onsite 3D body scanner. The advantage to this approach is that it allows direct personalization of figural stimuli and immediate feedback using the individual's 3D body model. Further, the individual's scan can be taken post-operatively as she returns for routine follow-up visits. The pre- and postoperative scans form an individualized series that documents weight loss. Each subsequent $3 \mathrm{~d}$ body model can then be assessed using traditional body image assessment techniques. This disadvantage is the cost and operation of placing a 3D body scanner within the clinic.

The other alternative is to use the statistical shapes provided by the database of collected 3D scans as an online service for body image assessment purposes. The advantage here is that no scanner is required. The disadvantage is that personalization of the process is lost.

\section{Method and Process using an on-site 3D body scanner}

Height and weight are recorded as part of the routine process workflow.

The weight loss surgery candidate is given a simple questionnaire containing two questions. The same two questions are asked before they have taken a 3D body scan, and after they have had their 3D scan.

These questions are: Do you know your waist and hip measurements? If so, could you please write them down. And: Do you have an idea of the shape of your body? Pear? Apple? In-between?

The six top level shapes are presented within part of this simple questionnaire. The weight loss surgery candidate circles the shape that they believe best represents their body shape prior to undergoing the 3D scan process. 
The weight loss surgery candidate then has their scan taken and receives their printout. The measurements on the printout are common circumferential measurements, and includes images of their front and side profile. It is recommended that certain measurements such as wrists, elbows and ankles be omitted as these can vary dramatically based on the posture of the individual within the scan chamber.

The shape descriptors are then calculated from the information within their 3D body model and their shape classification is determined. Their 3D body model is exported to a post-processing program for volumetric scaling.

Once they have their printout, measurement and shape description they are then asked to fill out the answers to the same two questions, which are presented again at the end of the form.

This initial process helps determine the individual's understanding of their body shape and size, and sets the stage for the next step, which is computerized.

They then select the top level shape with which they most associate (Figure 12), now having the knowledge of their general shape and measurements. All selections are electronically recorded.

This top level selection is then expanded to show the volumetrically accurate figural stimuli (Figure 13). Because we know their approximate weight loss at particular intervals after surgery, their predictive weigh loss models are shown. Further, these scaled 3D body models are imported into the scanner measurement program and their predictive circumferential measurements are extracted. This gives the pre-operative surgical weight loss patient an expected post-surgery weight loss path.

The three common BIA questions are asked and tabulated: 1. Which body shape best represents your current shape? 2. Which body shape best represents your ideal body shape 1 year after weight loss surgery? 3. Which body shape would you feel most comfortable maintaining?

Other BIA-like tests can be administered as required or desired. The results are compiled and evaluated by the staff psychologist as part of the overall pre-operative evaluation examination.

\section{Method and Process without using as onsite 3D body scanner}

A similar process can be done without the presence of a 3D body scanner, but there is no personalization capability. Instead, the individual selects a series of statistical images based on their height and weight and their waist and hips measurements. By nature, it is difficult to manually measure morbidly obese individuals, so their waist and hips measurements will be an approximation.

The six top level images are presented in electronic form, and the individual selects one of these shapes that best their concept of the shape they have. Based on the height, weight and measurement information, a series of volumetrically scaled images are presented, and the BIA questions are then administered.

\section{Summary and Conclusion}

We have seen how body image analysis has emerged as an important and practical area of study. It started in the mid-1930's, coincident with the nascent forms of mass-media distribution from the motion picture centers of the world. Nationalized images were promulgated and accepted as "ideal" body images. These images, while entertaining, were not obtainable for the great majority of the population. Technological breakthroughs in agriculture, the development of the processed food industry, and convenient outlets for food distribution at a relatively low cost has, in part, contributed to the current "obesity epidemic." "Ideal" body images continue to be promoted in popular media that are increasingly unobtainable. Certain segments of the population, such as adolescent girls became particularly susceptible to these images. As a result, early efforts to assess, quantify and measure perceptions of one's body image tended to focus on this segment of the population, where cases of eating disorders emerged.

As an aid to body image analysis, figural stimuli were introduced. These figures tended to be impersonalized and somewhat cartoonish, but they managed to get the individual to assess their own shape by identifying with one of the images within the group of figural stimuli. Important studies were conducted in the late 1980's through the early 2000's, as the realm of body image analysis increased in scope. New figural stimuli were produced that were addressed to assess the increasingly obese population. 
As advances in $3 \mathrm{D}$ scanning came to the fore, attempts were made to utilize this technology to create personalized figural stimuli. The capability to "morph" the size of an image was introduced.

In the mid-2000's, 3D body scans of obese individuals began to take place. Thousands of scans were collected and analyzed. Mathematical formulas were created to classify the shape of the obese individual. This helped to create statistical "top level" shapes that span the universe of the shapes of the morbidly obese. Moreover, these 3D body models could be scaled volumetrically with precision, allowing the creation of a set of figural stimuli reflective of the shape and size of the individual at various stages of weight loss or weight gain.

In this decade, enough 3D scan data has been collected to produce extensive sets of realistic 3D figural stimuli that may assist the psychologist in assessing the pre-operative weight loss surgery patient's disposition toward their own body and assess their suitability for weight loss surgery. This can now be done in a consistent, objective and automated fashion, either with ad onsite 3D body scanner, or without.

While this effort has been focused on body image assessment for the obese, the framework architecture can be utilized and applied to broader areas of body image assessment.

\section{References}

1 Schilder, P. (1935/1950). The image and appearance of the human body. New York: International Universities Press.

2 Fisher, S. (1990). The evolution of psychological concepts about the body. In T. F. Cash \& T. Pruzinsky (Eds.), Body images:

Development, deviance, and change (pp. 3-20). New York: Guilford Press

3 http://www.ehow.com/about 5106547 history-high-fructose-corn-syrup.html

4 http://www.theobesityepidemic.org/introduction/

5 Fisher, S., \& Cleveland, S. E., (1968). Body image and personality (second revised ed.). New York: Dover Publications.

6 Fisher, S. (1970). Body experience in fantasy and behavior. New York: Appleton-Century-Crofts.

7 http://www.goodtherapy.org/learn-about-therapy/issues/body-image

8 http://www.psyctc.org/tools/bsq/pdf/

9 http://askmaryrd.com/tag/stunkard-silhouettes/

10 http://www.nature.com/ijo/journal/v24/n10/full/0801363a.html

11 Summary excerpts taken from http://ajcn.nutrition.org/content/80/3/794.2.full? relatedurls=yes\&legid=ajcn;80/3/794-a

12 http://www.slideshare.net/EmanuelMian/body-image-a-new-method-for-the-assessment

13 Complete Spacial Evaluation of the Preoperative Bariatric Patient: New Insights into Body Composition. Stephen D. Wohlgemuth, M.D., David Stefan, M.S.E.E. Paper ID 532013 3D Body Scanning Conference. Long Beach, CA. USA. October 2013. DOI: http://dx.doi.org/10.15221/13.340

14 Categorizing the Morbidly Obese Body Shape and Estimating Body Appearance Outcome before Weight Loss Surgery using 3D Anthropometric Data. David B. Stefan, M.S.E.E; David A. Gilbert, M.D. Paper ID 102015 3D Body Scanning Conference. Lugano, CH. October 2015. DOI: $10.15221 / 15.038$

15 Theory and Practical Steps to Introducing a new 3D Public Health Indicator to replace BMI Using Existing Population-based Multidimensional Reference Measurement Sets. David B. Stefan, M.S.E.E, Stephen D. Wohlgemuth, M.D., David A. Gilbert, M.D. Paper ID 552014 3D Body Scanning Conference. Lugano, CH. October 2014. DOI: $\underline{10.15221 / 14.299}$ 